\title{
Does the Excessive use of Mobile Phones in Young Adults Reflect an Emerging Behavioral Addiction?
}

\author{
Ritu Nehra, Natasha Kate, Sandeep Grover, Nitasha Khehra, Debasish Basu
}

\begin{abstract}
Background and objective: Mobile phones have become an essential part and parcel of modern life. Some of the studies have shown potentially adverse consequences of excessive mobile phone use. Aim of this study was to explore the pattern of mobile phone use among young adults and evaluate the mobile phone use pattern on the substance dependence criteria and assess the adverse consequences of mobile phone use.
\end{abstract}

Materials and methods: A 46-item questionnaire based on the ICD-10 substance dependence syndrome criteria, CAGE questionnaire and keeping the possible adverse consequences of excessive use in mind was given to the participants.

Results: A total of 212 young adults with a mean age of 21.6 years participated in the study. About one-third of the participants met three or more of the ICD-10 diagnostic criteria for substance dependence and more than half (57.1\%) fulfilled two or more items on the CAGE questionnaire. Those who fulfilled the dependence criteria spent more time per day on the mobile phone and more frequently had harmful consequences on various aspects of life.

Conclusion: Excessive mobile phone use is associated with adverse consequences in different spheres of life and some subjects use it in dependent pattern.

Keywords: Mobile dependence, Health consequence, Prevalence, India.

How to cite this article: Nehra R, Kate N, Grover S, Khehra N, Basu D. Does the Excessive use of Mobile Phones in Young Adults Reflect an Emerging Behavioral Addiction? J Postgrad Med Edu Res 2012;46(4):177-182.

Source of support: Nil

Conflict of interest: None

\section{INTRODUCTION}

Over the last 15 years there has been tremendous growth in the use of mobile phones because of its usefulness in communication and interactions in the sphere of work and private life. Besides communication, mobile phones have been used for other purposes like of playing games, listening to music, etc. Studies have also shown that use of mobile phone for social networking and e-mail has helped to reduce loneliness ${ }^{1}$ and in making friends. ${ }^{2}$ Resultantly mobile phones have become part and parcel of life of the user. Further, mobile phones have been used for smoking cessation $^{3}$ and management of severe mental disorders. ${ }^{4,5}$

However, excessive use of mobile phone is also associated with negative health consequences. The various negative consequence of mobile phone use include exposure to electromagnetic fields, headaches, earache and warmth sensations, perceived concentration difficulties, fatigue, dizziness, facial dermatitis, ${ }^{6-10}$ development of brain tumors $^{11,12}$ frustration ${ }^{1,7}$ and musculoskeletal symptoms due to intensive texting. ${ }^{13}$ Also, electromagnetic radiations have been thought to affect the sleep electroencephalogram ${ }^{14}$ and melatonin production. ${ }^{15}$ Mobile phone use while driving has been associated with increased incidence of road traffic accidents. ${ }^{16,17}$

However, in recent times, some of the studies have focused on the psychosocial consequences of mobile phone use. A recent prospective study showed that at 1 year of follow-up, increased mobile phone use is associated with symptoms of depression in subjects of either gender and increased sleep disturbances in men. ${ }^{18}$ Further, it is suggested that excessive mobile phone use have been associated with deterioration in the family life as one of the members attends phone calls ignoring those involved in the face to face conversation. ${ }^{19}$ Another recent study from Japan, involving 94,777 adolescents showed that use of mobile phone for calling and for sending text messages after lights out was associated with sleep disturbances in the form of short sleep duration; subjective poor sleep quality, excessive daytime sleepiness and symptoms of insomnia. ${ }^{20}$

Considering the excessive use of mobile phone, some authors have developed questionnaires for the assessment of problematic mobile use, psychological consequences of mobile phone use and mobile phone addiction. ${ }^{21-26}$

Studies which have evaluated mobile addiction, have shown that some of the participants meet the criteria of excessive use in terms of economic cost and amount of use, problems with parents due to excessive use, sociooccupational dysfunction, psychological withdrawal and tolerance ${ }^{27}$ Other studies suggest that majority of the mobile addicts are teenagers, who are shy and have low selfesteem. ${ }^{28}$ Authors have also described disorders like textaphrenia (thinking that they have heard a message come in or felt the device vibrate when it actually has not), textiety (feeling anxious of not receiving any texts or not being able to send any), post-traumatic text disorder (physical and mental injuries related to texting) and binge texting (sending multiple texts to feel good about themselves and to attract responses).

India has the 2nd largest mobile phone customer base, after China and the customer base is expanding in India at a faster pace than that of China. However, no systemic data 
that have evaluated the abuse and dependence potential of mobile phone use are available from India.

Considering the increasing interest in behavioral addiction and lack of data from India, the present study attempted to explore the pattern of mobile phone use among young adults pursuing graduation and postgraduation. The secondary aim was to evaluate their mobile use on the International Classification of Diseases-10th edition (ICD-10) Classification of Mental and Behavioral Disorders Criteria of substance dependence syndrome ${ }^{29}$ and the CAGE questionnaire $^{30-32}$ and to assess the adverse consequences of mobile phone use in dependent pattern.

\section{MATERIALS AND METHODS}

A 46-item self-rated questionnaire with 'yes/no' responses was specifically designed for the purpose of the study. The items were designed in such a way as to provide information about the pattern of mobile use, to assess as to whether use pattern fulfilled the ICD-10 criteria for substance dependence syndrome and substance dependence as per the CAGE questionnaire. Of the 46 items, 26 covered the ICD-10 dependence syndrome (2 question for desire, 2 for tolerance, 5 for withdrawal, 5 for persistence despite harm, 11 for dyscontrol and 1 item for neglect of pleasurable activity) and 4 items covered the CAGE questionnaire. One item evaluated the family history of substance dependence and rest of the 15 items reflected the mobile use in general especially focusing on the harmful consequences. For a participant to have fulfilled a specific criterion of the ICD-10 covered by multiple questions (i.e. >1 question), they were considered to have done so, if they responded positively for at least $50 \%$ of questions covering that criterion.

Students pursuing graduation courses (Bachelor of Dentistry, Bachelor of Medicine and Surgery Bachelor of Arts, Commerce or Science) and Postgraduation courses (Masters in Arts, Masters in Medicine or Surgery and allied branches) were approached by purposive sampling. They were explained about the purpose of the study and those provided verbal consent to participate were invited to complete the questionnaire.

Data was analyzed using SPSS-14. For the various nominal variables, frequencies and percentages were calculated. For the continuous variables mean and standard deviation was calculated. Associations between different variables were studies by using Pearson product moment correlation and Spearman rank correlations. Comparisons were done using the Chi-square test and t-test. Intraclass correlation coefficient was used to evaluate the concordance between ICD-10 criteria and CAGE questionnaire.

\section{RESULTS}

The study included 212 young adults, with a mean age of 21.6 years (SD-3.22; range 18-30). Three fourth $(\mathrm{N}=158$; $74.5 \%$ ) of them were females. In most of the cases, it was family's decision (52.4\%) to give a mobile phone to the participant and in $40.6 \%$ of the cases it was the person's own decision to have a mobile phone. In others, it was joint decision.

On an average, the participants were spending 58.8 (SD-68.4; range 0-390) minutes/day on making phone calls and the mean number of calls made per day were 8 (SD13.2; range 0-120) minutes/day. Of the 212 participants, $41 \%$ were spending atleast 1 hour per day in making calls. The time spent in receiving calls exceeded the time spent on calling and the mean duration of calls received was 60.9 (SD-60.6; range $0-330$ ) minutes/day and $46.7 \%$ of the participants were spending atleast 1 hour in receiving the phone calls. The amount spent on messaging was 31 (SD57.4; range 0-480) minutes/day and the average number of messages sent per day were 10.4 (SD-16.8; range 0-100) per day. Only $8 \%$ of the participants were spending at least 1 hour in texting the messages. Additionally they spent 18.6 (SD-44.8; range 0-300) minutes/day on playing games on the mobile phones and only $6.6 \%$ of the participants were spending atleast 1 hour per day in playing games on the mobile phone.

Overall the mean duration of time spent per day on mobile phone was 169.4 (SD-154.9; range 3-760) minutes per day.

Responses to questions evaluating the mobile phone use pattern are shown in Table 1. More than two-third (69.8\%) of the participants answered positively for the 'Does using mobile phone help you to overcome the bad moods (e.g. feeling of inferiority, helplessness, guilt, anxiety, depression, etc.)?' and nearly equal number of participants answered affirmatively for 'Do you think that excessive use of mobile phone is harmful to your health?'. Other facts reported positively by about half of the sample were: Keeping the mobile phone switched on during the daytime, even though getting disturbed by the same (59.4\%), getting upset when mobile phone is not available (58.5\%), keeping the mobile phone switched on during the daytime, even though getting disturbed by the same at the relaxation time (58\%), feeling of guilt due to expenditure (56.6\%), feeling uneasy on forgetting the mobile (55.2\%), getting irritated on not able to locate the mobile in the morning (49.5\%) and feeling of incompleteness, if not able to access the mobile phone (49.1\%).

\section{MOBILE DEPENDENCE}

Based on the responses to the various questions, ICD-10 criteria were applied. For some of the criteria, responses to 
more than one question were considered (see Table 2) and in such a scenario, if the participant answered in 'yes' to $50 \%$ of questions picking up that criterion, then it was considered that the participants fulfilled that ICD-10 criterion.
Among the ICD-10 diagnostic criteria, most commonly met diagnostic criteria fulfilled was that of intense desire (56.6\%), followed by withdrawal (42.9\%), tolerance (42.5\%), persistence despite harm (19.3\%), neglect of alternative pleasure (11.3\%) and impaired control (8\%).

\begin{tabular}{|c|c|c|}
\hline & Questions & $N(\%)$ \\
\hline 14 & $\begin{array}{l}\text { Does using mobile phone help you to overcome the bad moods (e.g. feeling of inferiority, helplessness, } \\
\text { guilt, anxiety, depression, etc.)? }\end{array}$ & $148(69.8)$ \\
\hline 16 & Do you think that excessive use of mobile phone is harmful to your health? & $147(69.3)$ \\
\hline 21 & $\begin{array}{l}\text { Do you keep the mobile phone switched on during the daytime even though you know that keeping it on } \\
\text { will disturb you, if you are going to bed? }\end{array}$ & $126(59.4)$ \\
\hline 5 & Do you get upset when mobile phone is not available? & $124(58.5)$ \\
\hline 22 & $\begin{array}{l}\text { Do you keep the mobile phone switched on during the daytime even though you know that keeping it on } \\
\text { will disturb you, if you want to relax? }\end{array}$ & $123(58.0)$ \\
\hline 17 & Do you feel guilty about the expenditure (excessive) mobile phone? & $120(56.6)$ \\
\hline 36 & $\begin{array}{l}\text { Do you become uneasy, if you forget your mobile phone at some place although you know that it is at } \\
\text { safe place, and remain preoccupied with the same till you get back your mobile? }\end{array}$ & $117(55.2)$ \\
\hline 40 & Do you get irritated in the morning, if you are not able to locate your mobile phone? & 105 (49.5) \\
\hline 33 & Do you have a feeling of incompleteness, if you are not able to access the mobile phone daily? & $104(49.1)$ \\
\hline 11 & Do you become anxious of missing something, if you have to switch off your mobile for some reason? & $97(45.8)$ \\
\hline 27 & $\begin{array}{l}\text { When busy in your studies for long hours, do you keep on checking your mobile phone in anticipation of } \\
\text { a call or a message? }\end{array}$ & $97(45.8)$ \\
\hline 10 & Does using mobile phone provide as escape from the problems? & $91(42.9)$ \\
\hline 4 & Do you get upset when attempting to cut down mobile phone use? & $83(39.2)$ \\
\hline 7 & Do you lose track of time after starting to use mobile phone for SMS, games, music, etc.? ${ }^{3}$ & $77(36.3)$ \\
\hline 13 & Do you call back to most missed calls? & $74(34.9)$ \\
\hline 46 & $\begin{array}{l}\text { Do you become uneasy, if you forget your mobile phone at some place, at times go back immediately to } \\
\text { get it back although you know that it is at safe place, leaving behind other important work? }\end{array}$ & $73(34.4)$ \\
\hline 31 & Do you get annoyed or shout, if someone asks you to decrease the use of mobile phone? & $65(30.7)$ \\
\hline 44 & Has the mobile phone use increased over the years without any logical explanation? & $60(28.3)$ \\
\hline 1 & $\begin{array}{l}\text { When not using the mobile, are you often preoccupied with the mobile phone (keep thinking about the } \\
\text { previous and future uses) }\end{array}$ & $52(24.5)$ \\
\hline 38 & Are you able to stop yourself from sending SMS for various competitions? & $52(24.5)$ \\
\hline 3 & Have you made unsuccessful efforts to control, decrease or stop mobile phone use? & $49(23.1)$ \\
\hline 2 & Do you need to use the mobile phone for increased amount of time in order to achieve satisfaction? & $46(21.7)$ \\
\hline 34 & Do you get annoyed with your family members, if your talk time is finished? & $44(20.8)$ \\
\hline 37 & Do you frequently participate in sending SMS for various competitions? & $43(20.3)$ \\
\hline 26 & Do you compromise on spending on other aspects of life to meet the expenditure of mobile? & 40 (18.9) \\
\hline 25 & Do your families/friends or colleagues complain that your mobile phone use is excessive? & $37(17.5)$ \\
\hline 30 & Has mobile phone use led to decrease in socialization? & $37(17.5)$ \\
\hline 42 & Do others regard your time spent on mobile as unreasonable? & $37(17.5)$ \\
\hline 24 & Do your families/friends or colleagues complain that you spend too much time on mobile phone? & $36(17)$ \\
\hline 43 & Do you feel that life would have been better without the mobile phone? & $34(16.0)$ \\
\hline 12 & $\begin{array}{l}\text { Do you compulsively respond to calls/SMSs at places which do not permit (class, driving, } \\
\text { group participation) you to do so? }\end{array}$ & $31(14.6)$ \\
\hline 28 & $\begin{array}{l}\text { Do you or your family believe that you changed your sleep pattern or sacrificed sleep in order to } \\
\text { spend time on the mobile phone? }\end{array}$ & $30(14.2)$ \\
\hline 45 & Has the mobile phone use led to any accident? & $29(13.7)$ \\
\hline 8 & Do you lie to others to conceal the extent of your use of mobile phone? & $26(12.3)$ \\
\hline 15 & Have you drastically changed your life style in order to keep yourself busy on mobile phone? & $24(11.3)$ \\
\hline 20 & Do you keep on using mobile phone when your education expects you to work on other things? & $24(11.3)$ \\
\hline 9 & Has mobile phone made you spend less time with family members? & $23(10.8)$ \\
\hline 18 & Do you indulge in messaging and playing games at inappropriate places? & $22(10.4)$ \\
\hline 35 & $\begin{array}{l}\text { Has any of your family members (blood relatives) used alcohol or any drug leading to marked } \\
\text { dysfunction in social or occupational functioning? }\end{array}$ & $20(9.4)$ \\
\hline 19 & Has mobile phone use deprived you an educational opportunity? & $18(8.5)$ \\
\hline 6 & Has mobile phone use led to loss of friends? & $17(8)$ \\
\hline 32 & Have your grades in studies gone down due to the mobile phone use? & $16(7.5)$ \\
\hline 41 & $\begin{array}{l}\text { Do you indulge in behaviors like sending messages and talking to unknown people of } \\
\text { same and/or opposite sex? }\end{array}$ & $14(6.6)$ \\
\hline 23 & Has mobile phone use risked or jeopardized you of a career opportunity? & $13(6.1)$ \\
\hline 39 & Do you exchange/view pornography on mobile phone? & $10(4.7)$ \\
\hline 29 & Do you skip classes or appointments so as to spend time using the mobile phone? & $7(3.3)$ \\
\hline
\end{tabular}


Overall 33.5\% of the participants met three or more of the ICD-10 diagnostic criteria suggestive of addiction. Similarly the participants were evaluated on the CAGE criteria based on the responses to one question for each construct. More than half (57.1\%) of the participants had a score of two or more on the CAGE questionnaire.

\section{PREDICTORS OF DEPENDENCE}

When we compared the mobile use pattern (duration of phone calls made, duration of phone calls received, time spent in sending SMS, time spent in playing games, mean number of calls made per day and mean number of SMS sent per day) of those fulfilling ICD-10 dependence criteria with those not fulfilling the dependence criteria, those fulfilling the criteria spent significantly more time in making calls (Mann-Whitney U value 3923.5; $\mathrm{p}=0.01$ ), receiving calls (Mann-Whitney U value 3980; $\mathrm{p}=0.014$ ), sending messages (Mann-Whitney U value 3987; $p=0.015$ ) and number of calls made per day (Mann-Whitney U value 3961; $p=0.013$ ). When similar comparison was made with respect to CAGE questionnaire, significant differences were not seen in any of these variables between those who fulfilled 2 or more and those fulfilled $<2$ CAGE questionnaire items.

Overall it was also seen that those who fulfilled ICD-10 criteria used the mobile phone for significantly longer duration than those who did not fulfilled ICD-10 criteria (t-value 4.04; $\mathrm{p}<0.001$ ). Further, it was seen that total duration of mobile phone use per day correlated significantly with number of ICD-10 criteria fulfilled (Pearson's product moment correlation 0.302; $\mathrm{p}<0.001$ ) and number of CAGE questionnaire responses (Pearson's product moment correlation 0.237; $\mathrm{p}=0.001$ ).

\section{CORRELATION BETWEEN ICD-10 CRITERIA AND CAGE QUESTIONNAIRE ITEMS}

There was significant correlation between those fulfilling ICD-10 criteria and those with $\geq 2$ responses on CAGE (Pearson's product moment correlation 264; p < 0.001).

\section{COMPARISON OF CONSEQUENCES OF DEPENDENCE}

As shown in Table 3, those fulfilling the dependence criteria more frequently had harmful consequences on various aspects of life. Of the 15 items studied, significant difference was seen on 12 out of 15 items.

\section{DISCUSSION}

This was a preliminary survey to understand the mobile use pattern in young adults. For this 212 young adults pursuing various courses were approached by purposive sampling. Findings of this study suggest that on an average young adults use their mobile phone for 3 hours/day for making and receiving calls, sending messages and playing games. Further, it was seen that about one-third of the participants fulfilled ICD-10 criteria for dependence. This finding suggests that excessive mobile phone use also should be looked from behavioral addiction point of view and specific criteria should be formulated for the same. However, besides fulfilling the dependence criteria, present survey also suggest that the mobile use pattern, especially in those fulfilling addiction patterns has many harmful consequences.

In the present survey, the question which received the maximum number of positive responses was 'Does using mobile phone help you to overcome the bad moods (e.g. feeling of inferiority, helplessness, guilt, anxiety, depression etc.)?' More than two-third of the participants answered in 'yes' to this question. Further, slightly more than $40 \%$ of the participants used mobile phones as an escape from their problems and about one-sixth of the participants admitted that mobile phone use led to reduction in socialization. Further, many of the adverse consequences were significantly more common in those fulfilling the dependence criteria. However, it is difficult to draw exact conclusions regarding this, as the participants were not interviewed. Studies from West have also shown that mobile

Table 2: Number of participants meeting the ICD-10 diagnostic criteria

ICD-10 diagnostic criteria

- Intense desire $(\mathrm{Q}-1,33)$

- Impaired control (Q-3, 7, 12, 13, 24, 25, 27, 29, 38, 41, 42)

- Withdrawal (Q-5, 11, 34, 36, 46)

- Tolerance $(\mathrm{Q}-2,44)$

- Neglect of alternate pleasure (15)

- Persistence despite harm (Q-21, 22, 28, 43, 45)

CAGE questionnaire item

- Cut down (Q-4)

- Annoyance (Q-31)

- Guilt (Q-17)

- Eye opener (Q-40)

- Met $\geq 2$ CAGE questionnaire
Percentage of participants meeting the criteria

56.6

8

42.9

42.5

11.3

19.3

39.2

30.7

56.6

49.5

57.1 
Table 3: Comparison of harmful consequences in those fulfilling and those not fulfilling the ICD-10 criteria of dependence

\begin{tabular}{|c|c|c|c|c|}
\hline & & $\begin{array}{c}I C D-10 \\
\text { dependence } \\
\text { present }(N=71)\end{array}$ & $\begin{array}{c}\text { ICD-10 } \\
\text { dependence } \\
\text { absent }(N=141)\end{array}$ & $\begin{array}{c}\text { Chi-square } \\
\text { test value } \\
(p \text {-value })\end{array}$ \\
\hline 6 & Has mobile phone use led to loss of friends? & 9 & 8 & 3.13 \\
\hline 8 & Do you lie to others to conceal the extent of & & & \\
\hline & your use of mobile phone? & 15 & 11 & $7.79(0.005)$ \\
\hline 9 & Has mobile phone made you spend less time with family members? & 14 & 9 & $8.68(0.003)$ \\
\hline 10 & Does using mobile phone provide as escape from the problems? & 43 & 48 & $13.55(<0.001)$ \\
\hline 14 & $\begin{array}{l}\text { Does using mobile phone help you to overcome the } \\
\text { bad moods (e.g. feeling of inferiority, helplessness, }\end{array}$ & & & \\
\hline 16 & $\begin{array}{l}\text { guilt, anxiety, depression, etc.)? } \\
\text { Do you think that excessive use of mobile phone is }\end{array}$ & 60 & 88 & $10.93(<0.001)$ \\
\hline & harmful to your health? & 43 & 104 & $3.86(0.05)$ \\
\hline 18 & $\begin{array}{l}\text { Do you indulge in messaging and playing games at } \\
\text { inappropriate places? }\end{array}$ & 14 & 8 & $10.0(0.002)$ \\
\hline 19 & $\begin{array}{l}\text { Has mobile phone use deprived you an } \\
\text { educational opportunity? }\end{array}$ & 7 & 11 & 0.25 \\
\hline 20 & $\begin{array}{l}\text { Do you keep on using mobile phone when your } \\
\text { education expects you to work on other things? }\end{array}$ & 16 & 8 & $13.37(<0.001)$ \\
\hline 23 & $\begin{array}{l}\text { Has mobile phone use risked or jeopardized you of a } \\
\text { career opportunity? }\end{array}$ & 52 & 71 & $10.1(0.001)$ \\
\hline 26 & $\begin{array}{l}\text { Do you compromise on spending on other aspects of } \\
\text { life to meet the expenditure of mobile? }\end{array}$ & 28 & 12 & $30.2(<0.001)$ \\
\hline 30 & Has mobile phone use led to decrease in socialization? & 16 & 21 & 1.91 \\
\hline 32 & Have your grades in studies gone down due to the mobile phone use? & 9 & 7 & $4.02(0.05)$ \\
\hline 37 & Do you frequently participate in sending SMS for various competitions? & 26 & 17 & $17.62(<0.001)$ \\
\hline 39 & Do you exchange/view pornography on mobile phone? & 7 & 3 & $4.67^{\#}(0.03)$ \\
\hline
\end{tabular}

${ }^{\#}$ Chi-square value with yates' correction

phone is used for social networking to reduce loneliness ${ }^{1}$ and mobile phones addicts have low self-esteem ${ }^{28}$ and increased mobile phone use is associated with symptoms of depression. ${ }^{18}$ In about 10 to $15 \%$ of the participants of our study, the mobile use led to reduction in sleep, interpersonal relationship problems with family members to due to mobile use pattern, accidents and spending less time with family members. Studies from the west also suggest excessive phone use to be associated with sleep disturbances. ${ }^{18}$

All these suggest that there is an urgent need to carry out detailed research in the area of pattern of mobile phone use and the adverse consequences/outcomes of the same.

Our study was limited by small sample size and recruitment of subjects by purposive sampling. Further, the findings are based on self-rated questionnaire with dichotomous yes/no responses. The study did not evaluate various other behavioral patterns which could be associated with addiction in general and behavioral addiction in particular. The study did not focus on the personality, presence of comorbid substance use or other psychiatric morbidity, stress levels, etc. Future studies should include large sample selected by better sampling technique. A screening questionnaire like used in this study could be used to pick-up patients who may be possibly be having mobile addiction and they should be evaluated by the psychiatrists for personality traits, psychosocial issues leading to excessive mobile use and also psychosocial consequences of excessive mobile use. Further, these subjects should also be evaluated for presence of psychiatric morbidity.

\section{CONCLUSION}

This preliminary survey suggests that a large proportion of young adults in India are using mobile phones excessively. About one-third of the subjects fulfil ICD-10 criteria of dependence. Further the excessive use is associated with certain features suggestive of psychiatric morbidity, which may be a cause or effect of excessive mobile phone use. The excessive use of mobile phone in dependence pattern is associated with significantly higher negative psychosocial consequences. Hence, there is an urgent need to increase the awareness about this fact in general public. Further there is a need to study the mobile phone use more systematically.

\section{REFERENCES}

1. Ogata Y, Izumi Y, Kitaike T. Mobile-phone e-mail use, social networks, and loneliness among Japanese high school students. (Nippon koshu eisei zasshi) Jap J Pub Heal 2006;53: 480-92.

2. Kamibeppu K, Sugiura H. Impact of the mobile phone on Junior High School Students' Friendships in the Tokyo Metropolitan Area. Cyberpsychol Behav 2005;8:121-30.

3. Abroms LC, Padmanabhan N, Thaweethai L, Phillips T. iPhone apps for smoking cessation: A content analysis. Am J Prev Med 201;40:279-85.

4. Prociow PA, Crowe JA. Towards personalised ambient monitoring of mental health via mobile technologies. Technol Health Care 2010;18:275-84. 
5. Depp CA, Mausbach B, Granholm E, Cardenas V, Ben-Zeev D, Patterson TL, et al. Mobile interventions for severe mental illness: Design and preliminary data from three approaches. J Nerv Ment Dis 2010;198:715-21.

6. Szyjkowska A, Bortkiewicz A, Szymczak W, MakowiecDabrowska T. Subjective symptoms related to mobile phone use-a pilot study. Polski Merkuriusz Lekarski 2005;19: 529-32.

7. Khan MM. Adverse effects of excessive mobile phone use. Int J Occup Med Environ Health 2008;21:289-93.

8. Johansson A, Nordin S, Heiden M, Sandström M. Symptoms, personality traits, and stress in people with mobile phone-related symptoms and electromagnetic hypersensitivity. J Psychosomatic Res 2010;68:37-45.

9. Korpinen LH, Pääkkönen RJ. Self-report of physical symptoms associated with using mobile phones and other electrical devices. Bioelectromagnetics 2009;30:431-37.

10. Van den Bulck J. Adolescent use of mobile phones for calling and for sending text messages after lights out: Results from a prospective cohort study with a 1-year follow-up. Sleep 2007; 30:1220-23.

11. Hardell L, Carlberg M. Mobile phones, cordless phones and the risk for brain tumors. Int J Oncology 2009;35:5-17.

12. IARC, 2011. Available from URL http://www.iarc.fr/en/mediacentre/pr/2011/pdfs/pr208_E.pdf. Accessed on 13.06.2011

13. Ming Z, Pietikainen S, Hänninen O. Excessive texting in pathophysiology of first carpometacarpal joint arthritis. Pathophysiology 2006;13:269-70.

14. Loughran SP, Wood AW, Barton JM, Croft RJ, Thompson B, Stough C. The effect of electromagnetic elds emitted by mobile phones on human sleep. Neuroreport 2005;16:1973-76.

15. Wood AW, Loughran SP, Stough C. Does evening exposure to mobile phone radiation affect subsequent melatonin production? Int J Radiat Biol 2006;82:69-76.

16. McCartt AT, Hellinga LA, Bratiman KA. Cell phones and driving: Review of research. Traffic Inj Prev 2006;7:89-106.

17. Klauer SG, Dingus TA, Neale VL, Sudweeks JD, Ramsey DJ. The impact of driver inattention on near-crash/crash risk: An analysis using the 100-car naturalistic driving study data. DOT HS 810 594. Washington, DC: National Highway Traffic Safety Administration 2006.

18. Thomee S, Harenstam A, Hagberg M. Mobile phone use and stress, sleep disturbances, and symptoms of depression among young adults-a prospective cohort study. BMC Public Health 2011;11:66-76

19. Hubbard A, Han HL, Kim W, Nakamura L. Analysis of mobile phone interruptions in dating relationships: A face threatening act. Paper presented at the Annual Conference of the International Communication Association, San Francisco, CA, May 24-28, 2007.

20. Munezawa T, Kaneita Y, Osaki Y, Kanda H, Minowa M, Suzuki K, et al. The association between use of mobile phones after lights out and sleep disturbances among Japanese adolescents: A nationwide cross-sectional survey. Sleep 2011;34:1013-20.

21. Dimonte M, Ricchiuto G. Mobile phone and young people. A survey pilot study to explore the controversial aspects of a new social phenomenon. Minerva Pediatr 2006;58:357-63.

22. Beranuy Fargues M, Chamarro Lusar A, Graner Jordania C, Carbonell Sánchez X. Validation of two brief scales for Internet addiction and mobile phone problem use. Psicothema 2009;21: 480-85.
23. Rutland JB, Sheets T, Young T. Development of a scale to measure problem use of short message service: The SMS problem use diagnostic questionnaire. Cyberpsychol Behav 2007;10:841-43.

24. Chóliz M, Villanueva V. Questionnaire of dependence of mobile phone: Psychometric properties and gender differences (11th ed). European Congress of Psychology. Oslo, 7-10 July 2009.

25. Toda M, Monden K, Kubo K, Morimoto K. Mobile phone dependence and health-related life-style of university students. Soc Behav Pers 2006;34:1277-84.

26. Sanchez-Carbonell X, Beranuy M, Castellana M, Chamarro A, Oberst U. Internet and cell phone addiction: Passing fad or disorder? Adicciones 2008;20:149-59.

27. Chóliz M, Villanueva V, Chóliz MC, Ellas, ellos y su móvil: uso, abuso del teléfono móvil en la adolescencia. Revista Española de Drogodependencias 2009;34:74-88.

28. Takao M, Takahashi S, Kitamura M. Addictive personality and problematic mobile phone use. Cyberpsychol Behav Soc Netw 2009;12:501-07.

29. World Health Organization. The ICD-10 classification of mental and behavioral disorders. Clinical descriptions and diagnostic guidelines. Geneva: WHO, 1992.

30. Ewing JA. Detecting alcoholism: The CAGE questionnaire. JAMA 1984;252:1905-07.

31. Ewing JA, Rouse BA. Identifying the hidden alcoholic. Presented at the 29th International Congress on Alcohol and Drug Dependence. Sydney, Australia 1970, Feb 3.

32. Mayfield DG, McLeod G, Hall P. The CAGE questionnaire: Validation of a new alcoholism screening instrument. Am J Psychiatry 1974;131:121-23.

\section{ABOUT THE AUTHORS}

\section{Ritu Nehra (Corresponding Author)}

Additional Professor, Department of Psychiatry, Postgraduate Institute of Medical Education and Research, Chandigarh, India e-mail: ritu_nehra@rediffmail.com

\section{Natasha Kate}

Senior Resident, Department of Psychiatry, Postgraduate Institute of Medical Education and Research, Chandigarh, India

\section{Sandeep Grover}

Assistant Professor, Department of Psychiatry, Postgraduate Institute of Medical Education and Research, Chandigarh, India

\section{Nitasha Khehra}

Research Associate, Department of Psychiatry, Postgraduate Institute of Medical Education and Research, Chandigarh, India

\section{Debasish Basu}

Professor, Department of Psychiatry, Postgraduate Institute of Medical Education and Research, Chandigarh, India 